\title{
Before and After I Knew: Disclosure, Respect, Gratitude, and Solemnity
}

\author{
Susan E. Mackinnon M.D., FRCS(C), FACS; \\ Andrew Yee, Ph.D.
}

The Pernkopf anatomical atlas has contributed significantly to the specialty of nerve surgery through its infiltration in surgical training and the development of novel procedures due to the accurate depiction of the nervous system. Until the recent advancements of the Pernkopf controversy, nerve surgeons have struggled with the ethical dilemma presented with its use in surgery and clinical practice. In this article, we explore a personal story and reflection by an individual nerve surgeon, their contribution to the advancement of the Pernkopf controversy, and how different professional domains (surgery, anatomy, ethics, religion, and education) were able to collaborate to address the historical crimes against humanity and issues in the anatomical sciences. This required a structured approach to address this ethical dilemma in surgery, which included (1) an assessment of the use of the Pernkopf atlas in specific surgical specialties (nerve surgery and oral and maxillofacial surgery) and (2) the development of a graduated ethical framework with a religious framework (the Vienna Protocol), if the Pernkopf atlas was to be used in surgery. These studies are reviewed in the context of evolving paradigms in nerve surgery (nerve repair, grafting, and transfers) and influence of anatomy in the advancement of this surgical specialty.

\section{OPEN ACCESS}

I'm going to tell our story about before and after I met this atlas. When I was 19, I went to Queen's University. Harry Botterell, who was a neurosurgeon at the University of Toronto and led the team of neurosurgeons in the Second World War, was at Queen's. At the time I was there, he was Dean and moving into retirement. I remember during a summer day, I was sitting with Botterell in a small room with large windows, and he was talking about the effect of epinephrine on spinal cord injuries. I became fascinated in the subject, and little did I know that this was the exact moment when I would begin my career and devote my life to the nervous system. After being at Queen's from 1969-1978 and having two children with my husband, G. Alexander Patterson, in Kingston, we were offered jobs to return to Queen's after surgical training, if we elected to be trained at University of Toronto. I went to Toronto and completed my surgical training, and afterwards was sent for a fellowship to receive my training in hand surgery at the Curtis National Hand Center at Union Memorial Hospital in Baltimore, Maryland. Raymond Curtis was my mentor, and I was his last hand fellow. Curtis was trained by Sterling Bunnell, who started the specialty of hand surgery. In Baltimore my training as a hand surgeon was all about anatomy, whereas nerve surgery was considered an orphaned sub-specialty. The people that trained in the extremities were plastic and orthopedic surgeons, and the people that aspired to do surgery in the nervous system only focused on the spinal cord and brain. I gravitated to the anatomy labs. It was only after the fact, when I came back to Toronto - met Leila Lax and the people that were doing medical illustration, that I learned that the Art as Applied to Medicine program was first started by Max Brödel in 1911 at Johns Hopkins University in Baltimore. Brödel trained in Germany before coming to America. A Canadian, Maria Wishart, was one of Brödel's students in the class of 1925, and in 1945, she opened the Art as Applied to Medicine program at the University of Toronto.

It shouldn't be surprising that surgeons spending time in the Johns Hopkins anatomy lab, dissecting cadavers and learning the nervous system, would be using an anatomical atlas that was considered to be the very best and related to the German history of Brödel. I grew up with the atlas, which has two volumes: Head and Neck (Figure 1), and Thorax, Abdomen and Extremities. 


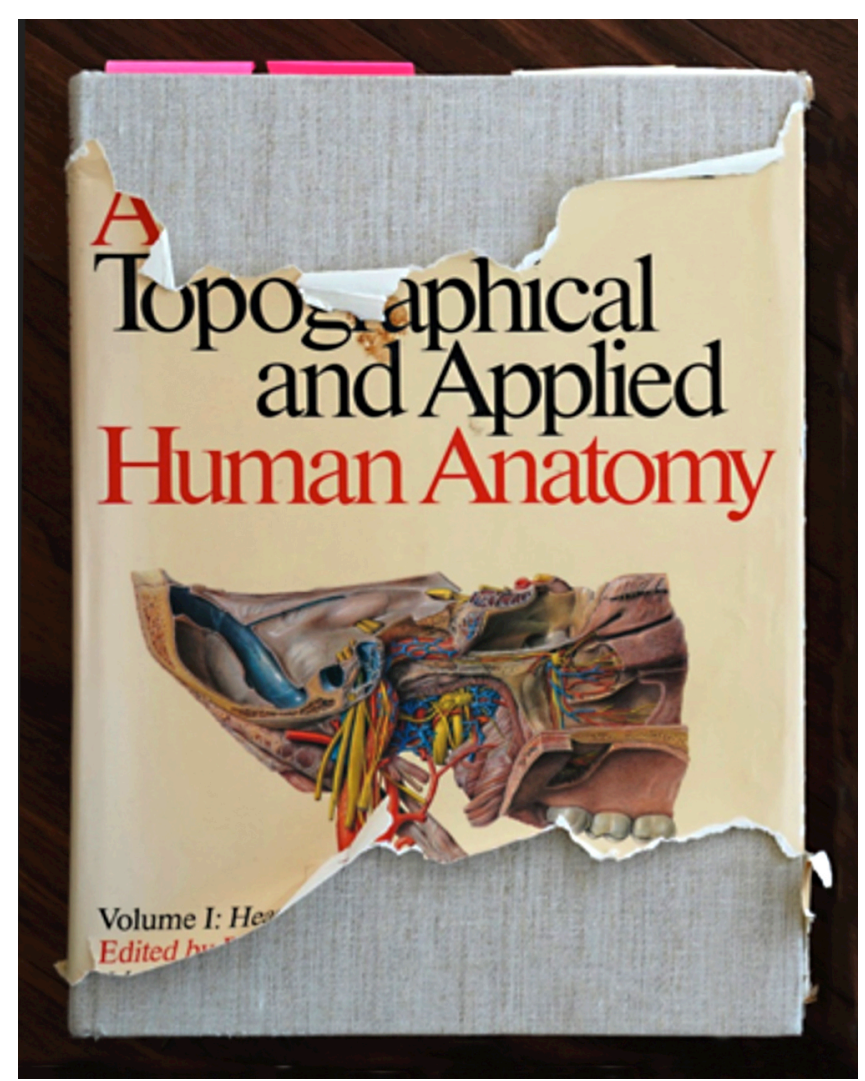

Figure 1. My copy of Volume 1 of the atlas (1980) over the years.

Naturally, people's anatomical atlases and textbooks are left next to the cadavers or nearby for the next dissection sessions, and I had thought about losing my copy of the atlas; residents are always borrowing books. In fact, I keep a Netter's Atlas in my clinic with a very specific note "don't take this - it is for me to teach my patients through the drawings in this book." With this concern, I bought a second set of the atlas and remember that each individual set cost $\$ 110$ in 1981-82. During my time in surgical practice, I would use the atlas to teach patients about their surgeries involving complex dissections like the brachial plexus, which in Netter's Atlas (2014) is illustrated quite simply. However, I used the atlas mostly to teach myself.

Andrew Yee, who started his career as my research assistant in 2007 and would later become a surgeon educator and received his doctorate in this work, was internationally recognized for his ability to translate my expertise in nerve surgery into videos. His work has become a new standard of multimedia teaching in surgery (Yee, Padovano, Fox, et al., 2020). Not only have we produced over 100 videos that have received millions of views, but we have also produced many anatomical photo plates of complex dissections for surgeons

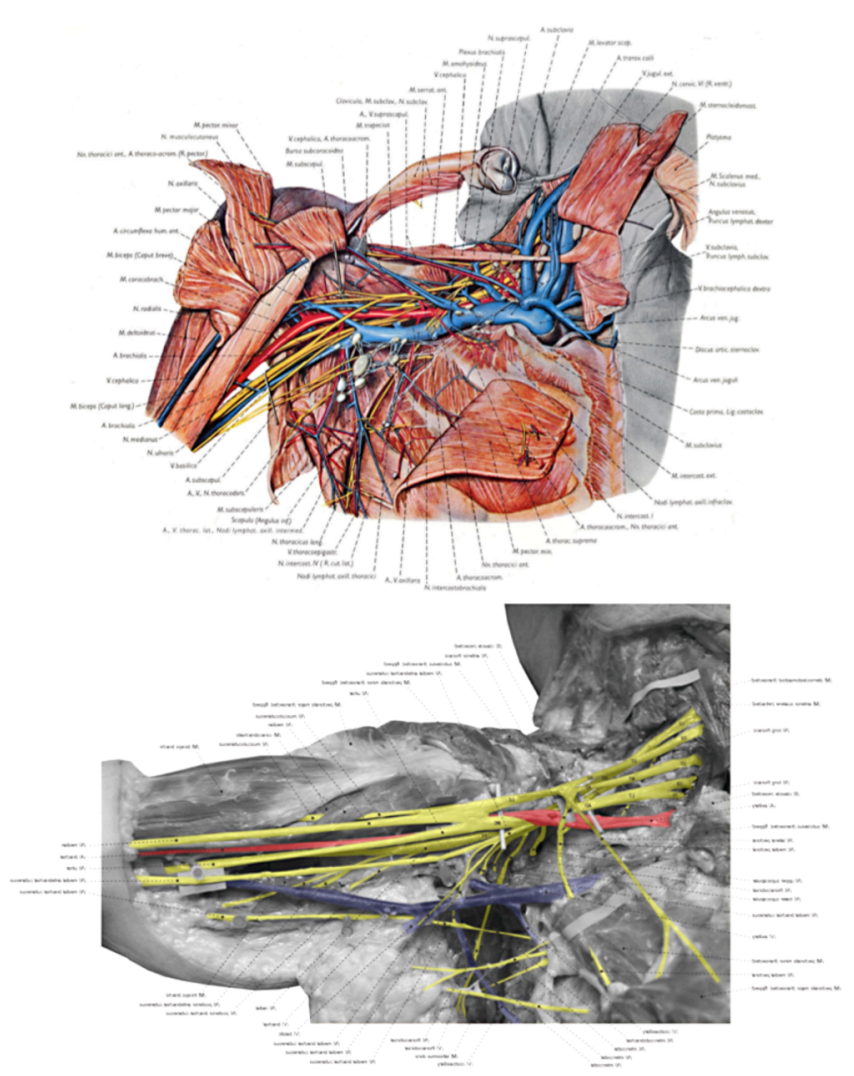

Figure 2. Top: Brachial plexus plate from the atlas (1980, Vol. 2, Fig. 36). Image credit: Medical University of Vienna, MUW-ZE-003250-000-0195r). Bottom: Dissection photo plate used in our anatomical resource. (Image credit: WUSTL Nerve Surgery, http://www.nervesurgery.wustl.edu).

to use with the videos. These included dissections of the brachial plexus using the atlas, while being oblivious to its history and the ethical implications in its use in surgery and education (Figure 2).

The atlas that I had was published in 1980. I didn't read the preface at the time and was only interested in looking at the plates - the medical illustrations. In preparation for the 2019 Holocaust Education Week Symposium at the University of Toronto, I read the preface from my 1980 edition, which was written by Helmut Ferner:

"The first edition of this atlas which appeared in 1963/64 in German, English, Italian and Japanese was received with great enthusiasm because of its high quality from scientific and technical viewpoints.... With a view toward the needs of the surgical specialties this edition represents a continuing effort to complement the illustrative material from the original drawings by [redacted] and his collaborating artists..." 

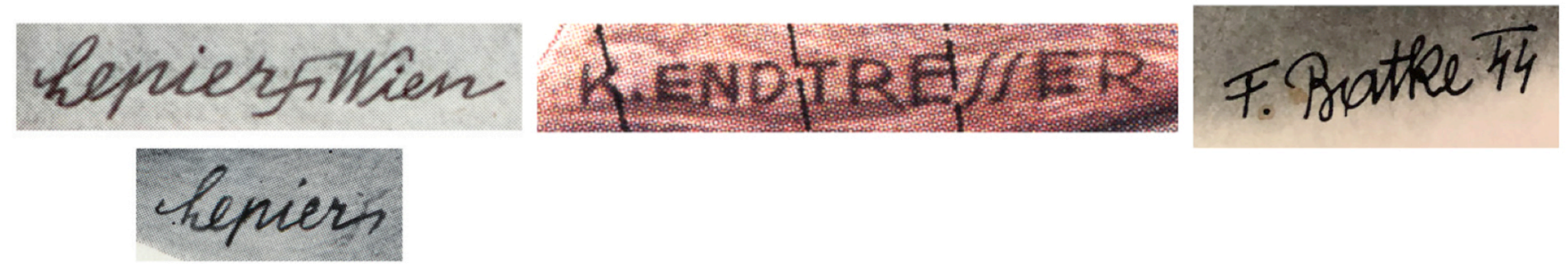

Figure 3. Different signatures of the atlas' artists with Nazi symbols. Lepier's signature with the removed swastika (lower left) is from my 1980 edition of the atlas. Image credits: Medical University of Vienna, MUW-ZE-003250-0005-0032, MUVAndruck-33611-Seite1, MUW-ZE-003250-0005-0538r.

There was no disclosure of the tainted history of the atlas, and if, in fact, by omission from the preface, it can be said that there could have been a cover-up of its origins. There certainly were not any swastikas in the signatures of the artists in my 1980 edition, however the thunderbolts remained. If you look carefully at Lepier's signature, you can see that the swastika was intentionally removed after the fact (Figure 3). Honestly, I didn't have a clue of what I was working with, as the thunderbolts were too subtle for me to easily associate with the Nazi regime (Figure 4).

After my training in Baltimore, I went back to University of Toronto to start my surgical practice in nerve surgery from 1982 to 1991. It was at the end of the 1980's, when I became aware of the history of the atlas and reflected on the impact its history had on me - before and after I knew. The use of the atlas for patient education and in surgery was deeply troubling and also embedded in my brain and my practice. If someone had said, "You have to burn those books." I would find it hard to do that.

That was the before and after. While I'm not sure of the exact date of when I initially knew, I do know at the time of a series of surgical illustrations made by Leila Lax with me - dated 1984 - neither of us knew. We didn't know of the atlas' history because no one really brought it to anyone's attention until the mid '80s when Gerald Weissman (1985), a physician from New York University, published his paper, and David Williams, a medical illustrator, published his detailed report in 1988 in the Journal of Biocommunication. I remember my first reaction when I knew - I was appalled, but I did not stop using the atlas.

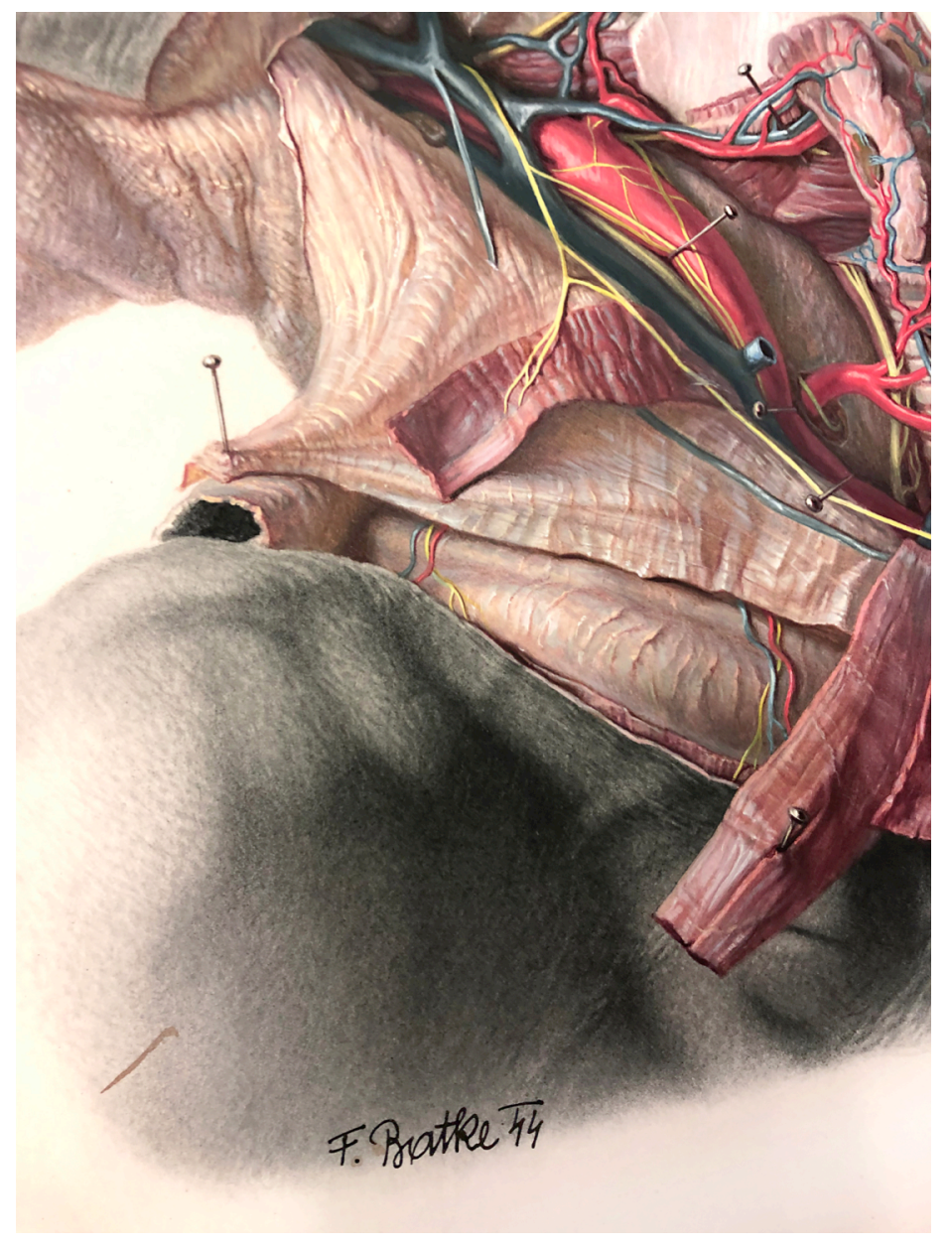

Figure 4. This original watercolor painting, published in the atlas, is an exemplary anatomical illustration. The visualization of the deep aspect of the right neck, with dissection of vessels and nerves, highlights the artistry and accuracy found in the atlas. Although this watercolor painting is 2-dimensional, the image gives the illusion of being 3-dimensional. The rendering of layered tissue planes and anatomical structures, coursing through different depths, along with the life-like attention to texture and relational details, provides critical information for a surgeon operating in this area. Image credit: Medical University of Vienna, MUW-ZE-003250-0005$0538 r$. 
Immediately after, I returned them to my operating room locker with reprints of both of Weissman and Williams' papers behind the front cover. Over the following years, like many surgeons who have focused on providing excellent care to their patients, we were troubled by the atlas' history, however we never knew the ethical approach to disclosure until my recent work with Yee. I've disclosed the history, when I have used it with students and others, and absolutely only used it when I needed it to help with surgery. I would use it before I went in the operating room for surgical planning, for patient education, and in the anatomy lab. Having Weissman and William's papers in my copies of the atlas was a reminder of its evil history. During my time in Toronto and moving forward - the atlas, and its artists, and the cadavers, and patients that I've operated on, have been part of my journey as a nerve surgeon. The fine details of nerve anatomy learned from the atlas are embedded in my brain.

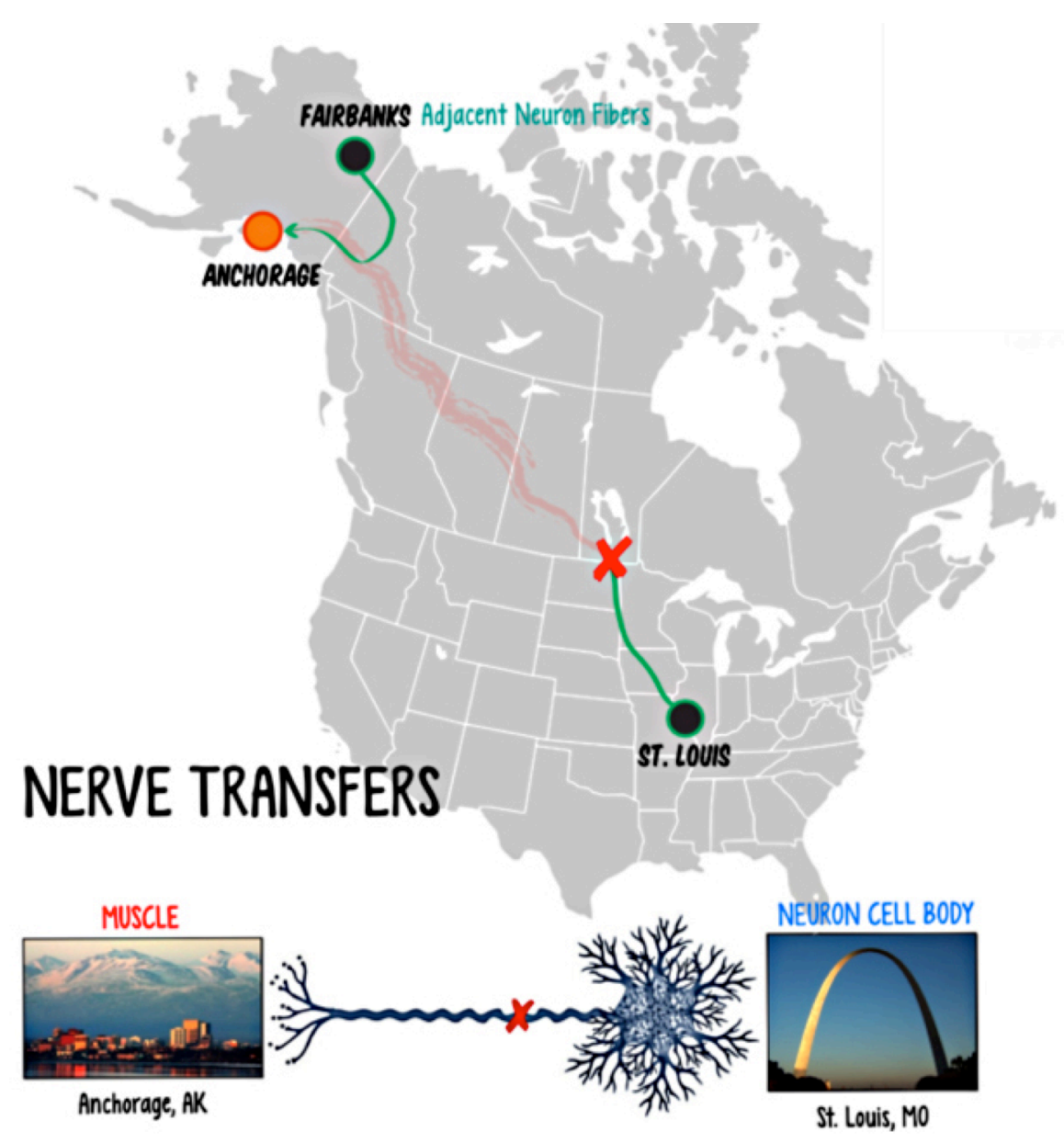

Figure 5. Nerve transfer analogy.
In my first major textbook on nerve surgery in 1988, called Surgery of the Peripheral Nerve, a Canadian medical illustrator by the name Terry Watkinson did my drawings. Over several decades later, by the time I published my second book in 2016 called Nerve Surgery, our knowledge of the median nerve internal topography has improved significantly to include the motor and sensory fascicles. Before then, especially those trained in hand surgery, surgeons have found it difficult to neurolysis these fascicles separately and precisely - because one wrong technical move and injury to these nerves can result either in lifealtering pain or loss of critical motor/sensory function. While the illustrations in the atlas didn't portray these fascicles specifically, what it did depict accurately were the nerve branches, where they branch distally, the volume of the branches compared to the proximal nerve - which one could indirectly determine internal fascicular anatomy, and its relationship to the micro vessels and vascular pedicles. It also provides accurate descriptions of tissue layers with precise labeling and detailed depictions of the very distal nerve branches.

In terms of nerve reconstruction, strategies for nerve repair coming out of the Second World War, for the most part, were tendon transfers. These strategies originated from the First World War. Management of nerve injuries and major defects shifted from nerve repair to nerve grafting in the 1970s. I became involved in nerve surgery when the paradigm of nerve repair started to shift to nerve grafting (Domeshek, Novak, Paterson, et al., 2019). For example, I performed long nerve grafting in one patient during the early 1980 s, to discover three years later that this patient's elbow flexion finally recovered with minimal function. By contrast, when an injury is at a similar proximal location - like in the neck or brachial plexus - nerve transfers have a significant advantage over grafting by using adjacent, healthy nerves to reinnervate the injured nerves distally and close to target. This technique of nerve transfer can be likened to "borrowing from Peter to pay Paul," and patients can recovery significant function within one year (Figure 5).

If the cell body of a nerve were as high as the Gateway Arch in St. Louis, Missouri - it would project an axon all the way up to 
Anchorage, Alaska. If there was a nerve injury at the Canadian-U.S. border and you repaired it with repair or grafting, it would take a very long time for supplies to reach to Anchorage. Not only would the people in Anchorage be dead by the time supplies reached Anchorage, the roads and pathway become more toxic over time and longer distances. By contrast, if you contact Fairbanks, Alaska, to distribute supplies like a nearby nerve, it will reach Anchorage faster, before the citizens of Anchorage wither away, and people would survive. That is my contribution to nerve surgery using nerve transfers - getting nerve fibers closer to a target faster.

In 1991, I was recruited to build a nerve surgery center and research lab studying nerve allotransplantation in St. Louis, Missouri. Almost two decades later, I met Andrew Yee who is a gifted individual in science and art and together, we started making instructional videos to encourage dissemination and implementation of novel practices in nerve surgery. We created an online video-based learning platform called PASSIO Education (Yee, Padovano, Fox, et al., 2020), which is Latin for passion and means "suffering enduringly," to train nerve surgeons and address the surgical disparities from learning new and expert operations. One Sunday afternoon in 2015, (Sundays are the days when Yee and I typically have fantastic working sessions), I proposed whether it would be possible to share the atlas's anatomical illustrations with our videos, and after much deliberate discussion involving disclosure and ethics, this began our journey to seek the advice and the opinions of the appropriate experts in the field.

I also spoke to my husband about this significant issue with the atlas, since he is the editor-in-chief for the Annals of Thoracic Surgery, an Elsevier journal. He connected us with his publishing editor, Andrew Berin, whom which I asked: "Andrew, can you help us get permission to use specific plates for education?" Berin proceeded to point us to Elsevier's office for permission, and they responded that Elsevier is unable to grant permission to use the atlas' images for academic peer-reviewed publications on education and ethics - due to the atlas' history. This response required us to consult Washington University's general counsel for guidance on whether we needed permission to discuss the ethics of using the atlas in surgery, which they agreed that this would be considered a fair use exception to the copyright law.

Around the same time on April 16, 2015, serendipitously, we noticed that Sabine Hildebrandt was giving a lecture on this very specific topic at Washington University and Barnes-
Jewish Hospital (Hildebrandt, 2015). She was invited as the 26th Annual Holocaust guest lecturer to present her soon to be published book titled "The Anatomy of Murder: Ethical Transgressions and Anatomical Science during the Third Reich" (Hildebrandt, 2016). I had to hear her talk in the morning. However, I also had to start a surgery and therefore went back to the operating room, told the staff to hold the case until I get back. While I walked with Yee to Hildebrandt's lecture, we discussed the implications of if she said "no," if we asked her "whether the atlas could be used for surgery and education?" After her talk, we approached her with this very specific question, provided her with background, and somewhat to our surprise and relief - she was receptive to this complex question and proposed that we perform an assessment of the current use of the atlas in nerve surgery, which promoted our first survey-based methods study.

What followed Dr. Hildebrandt's important lecture was a series of peer-reviewed studies discussing the ethical issues with the use of the atlas in surgery. As Hildebrandt recommended, we performed an assessment of the use of the atlas in nerve surgery (Yee, Coombs, Hildebrandt, et al., 2018). Individuals in this survey were my surgical peers in the American Society for the Peripheral Nerve and member surgeons who were registered in our PASSIO Education video-based learning platform. These nerve surgeons were asked questions whether they use the atlas in their practice and in what context. These questions were designed to develop a 4-point proposal for disclosure, bioethics and religious considerations, and remembrance. The results of this assessment revealed a minority of nerve surgeons (13\%) were actively using the atlas in their practice, and the majority found greater anatomical accuracy and surgical utility of this atlas compared with Netter's atlas.

Additionally, we found that the 4-point proposal shifted the majority of opinions by surgeons from being uncomfortable with the atlas' use to being comfortable (Yee, Coombs, Hildebrandt, et al., 2019; Yee, Zubovic, Yu, et al., 2019).

We found another opportunity to assess the use of the atlas in surgery, when we were introduced to Dr. Howard Israel and his specialty of oral and maxillofacial surgery (Yee, Li, Lilly, et al., 2021). We replicated the nerve surgery assessment in this specialty, and remarkably found a similar response in a different population of surgeons. These studies demonstrated the need to address the bioethics and religious considerations with the atlas since a framework did not exist yet. 
We approached Drs. Ira Kodner and Douglas Brown at our institution on how we might address the ethics of the atlas. Kodner is a retired colorectal surgeon and Brown is a bioethicist, who together created one of the first applied surgical ethics programs. They also introduced us to Michael Sarr, editor of the journal, Surgery, who recommended following an article format that included a unique graduated approach to addressing ethical issues in surgery (Yee, Zubovic, Yu, et al., 2018). This involved identifying an ethics issue and then outlining how might a surgeon address this issue in a linear and graduated approach with up to four different approaches having "all things considered". This manuscript would be the last study of an ethics series sponsored by the American College of Surgeons.

Knowing from our survey assessment that the religious aspect was a consideration to address, we introduced this format to Hildebrandt - who then introduced us to Rabbi Joseph Polak - Chief Rabbi of the Massachusetts Rabbinical Court and a child Holocaust survivor, and Prof. Michael Grodin - a bioethicist, at Boston University, whose expertise is centered on the Holocaust. With a panel of experts from diverse backgrounds, we were able to examine one example of the many cases that I encounter in my practice, specifically, a patient that had a chief compliant of debilitating neuropathic pain in the knee with a complex history of surgeries.

In this case, I needed the atlas due to the complex nature of the nerves in the region. The approach to address the ethical dilemma of use of the atlas with one's patient includes: (1) recognizing a time to call an operative time-out to reassess the surgical plan, (2) call a surgical colleague for emergency consultation, (3) take a time-out and consult an anatomy atlas, and (4) only if as a last resort to consult the atlas discussed in this article. Because I am considered an "end-ofthe-road" nerve surgeon, I do not know any other surgeon that might know the anatomy in this region more than myself, and it would be difficult for me to complete with ease without consulting the atlas.

This four-step approach to address the ethical dilemma involving the atlas also included a religious component titled "Jewish Ethics and Law," by Rabbi Polak and Michael Grodin. That component is part of a larger, important document, titled the Vienna Protocol (2017), that includes recommendations for the appropriate handling when Jewish or possibly-Jewish human remains are discovered and related to being victims of Nazi atrocities. We knew that including this religious section in our article is rare for a scientific and medical publication, and we did receive criticism from reviewers on this. However, this foreword by the religious authorities served as the basis of the framework when the religious consideration needed to be addressed, and was therefore included.

Since these important publications, I continue to keep the atlas in my operating room locker, even during my days in the clinic. Generally, I use the cartoons/simple illustrations from Netter's atlas to teach the basics to patients. However, if I need to teach the complexities of the diagnosis and management of nerve injuries, I will send someone to get the atlas from my locker and sit-down with the patient, disclose its history, and acquire their consent before looking through the atlas with them. In every circumstance, where I needed the atlas in my clinic, I haven't encountered an issue with the patient and the atlas. In fact, one of my patients has written their opinion in an invitational article for the British Medical Journal reviewing our work with the atlas (Mackinnon, 2020) (https://pubmed.ncbi.nlm.nih.gov/31974093/). What followed were key publications in many news outlets discussing the implications of our ethics studies (Baker, 2019; Begley, 2019; Berger, 2019, Kershner, 2020, Sohn, 2021), and I am humbled to be part of the story and remembrance of the lives that were lost with the atlas. When my husband and I were driving back-and-forth from our cottage in northern Ontario (10-hour trip), in 2019, we were talking about lots of things that included how to disclose to the patient the use of the atlas in their care. Being a cardiothoracic surgeon saving lives through lung transplantations and not limbs, he explained that "your patients want you to make them better and whatever it's going to take at that very moment in time - they just want to get over their pain and misery. They would like you to do that."

I have surgeons that visit my practice from around the world. In spite of our videos and giving away my techniques, they still come and visit because they are thirsty to learn the cognitive and clinical judgment involved with nerve surgery, which also includes addressing ethical issues. On typical days, these visitors will find the atlas in my locker with the ripped cover, and other days I receive questions from them asking where they might get a copy of their own, after learning of its history and how it is used in surgery. I would defer them to Yee, and hope for the day when there might be better ways for surgeons to access this material to help their patients with disclosure, respect, gratitude, and solemnity. 


\section{References}

Baker K. Eduard Pernkopf: The Nazi book of anatomy still used by surgeons. BBC. August 19, 2019.

Begley S. The surgeon had a dilemma only a Nazi medical text could resolve. Was it ethical to use it? STAT. May 30, 2019.

Berger E. Squaring an anatomy atlas' Nazi history with its potential to heal. St. Louis Jewish Light. December 19, 2019. Domeshek LF, Novak CB, Patterson MM, et al. Nerve Transfers - A Paradigm Shift in the Reconstructive Ladder. Plast Reconstr Surg Glob Open. 2019;7(6):e2290.

Hildebrandt S. The Anatomy of Murder: Ethical Transgressions and Anatomical Science during the Third Reich. 2015 Yom Hashoah Lecture for Medical Grand Rounds at the Department of Medicine; April 16, 2015; Washington University School of Medicine.

Hildebrandt S. The Anatomy of Murder: Ethical Transgressions and Anatomical Science during the Third Reich. New York: Berghahn Books; 2016.

Kershner I. In Israel, Modern Medicine Grapples With Ghosts of the Third Reich. The New York Times. May 12, 2020 .

Mackinnon SE, Dellon AL. Surgery of the Peripheral Nerve. Thieme; 1988.

Mackinnon SE. Nerve Surgery. New York, NY: Thieme Medical Publishers, Inc; 2015.

Mackinnon S. When medical information comes from Nazi atrocities. BMJ. 2020;368:17075.

Netter FH. Atlas of Human Anatomy. 6th ed: W. B. Saunders; 2014.

Pernkopf E. Atlas of Topographical and Applied Human Anatomy. Volume 1: Head and Neck. Volume 2: Thorax, Abdomen and Extremities. 2nd ed. Baltimore, Maryland: Urban \& Schwarzenberg; 1980.

Polak JA. "Vienna Protocol" for when Jewish or PossiblyJewish Human Remains are Discovered. In: Seidelman WE, Elbaum L, Hildebrandt S, eds. How to Deal with Holocaust Era Human Remains: Recommendations arising from a special symposium. Boston, MA: Elie Wiesel Center for Jewish Studies, Boston University; 2017.

Sohn R. Nazi anatomical drawings are donated in effort to address ethical quandary - and spotlight a dark history. STAT 2021; STAT

Weissmann G. Springtime for Pernkopf. Hosp Pract (Off Ed). 1985;20(10):142-168.

Williams DJ. The history of Eduard Pernkopf's Topographische Anatomie des Menschen. J Biocommun. 1988;15(2):2-12.

Yee A, Coombs DM, Hildebrandt S, Seidelman WE, Coert JH, Mackinnon SE. Nerve Surgeons' Assessment of the Role of Eduard Pernkopf's Atlas of Topographic and Applied Human Anatomy in Surgical Practice. Neurosurgery. 2018;84(2):491-498.

Yee A, Li J, Lilly J, et al. Oral and maxillofacial surgeons' assessment of the role of Pernkopf's atlas in surgical practice. Ann Anat. 2021;234:151614.

Yee A, Padovano WM, Fox IK, et al. Video-Based Learning in Surgery: Establishing Surgeon Engagement and

Utilization of Variable-duration Videos. Ann Surg. 2020;272(6):1012-1019.

Yee A, Zubovic E, Yu J, et al. Ethical considerations in the use of Pernkopf's Atlas of Anatomy: A surgical case study. Surgery. 2018;165(5):860-867.

\section{About the Authors}

Susan Mackinnon, MD, FRCS(C), FACS, was the Sydney M., Jr. and Robert H. Shoenberg Professor, and was the Chief, Division of Plastic and Reconstructive Surgery, Washington University, St. Louis, Missouri from 1996-2020. She currently holds the Minot Packer Fryer Chair of Plastic Surgery. Dr. Mackinnon trained and began her surgical career in Canada and in 1991 she joined the Washington University School of Medicine. Her notable research work has investigated nerve allotransplantation and nerve regeneration and has resulted in new strategies of nerve transfers to reconstruct nerve injuries. 
Andrew Yee, PhD is the Director of the Learn Surgery Program at Washington University School of Medicine, which is an online video-based learning program for surgeons to learn surgery. His research expertise is in the dissemination and implementation of surgical innovation in surgery using multimedia, instructional design, information technologies, and coaching.

\section{Susan E. Mackinnon M.D., FRCS(C), FACS}

Minot Packer Fryer Professor of Surgery,

Division of Plastic and Reconstructive Surgery, Department of Surgery, Washington University, St. Louis, Missouri

Contact: mackinnons@wustl.edu

\section{Andrew Yee, Ph.D.}

Division of Plastic and Reconstructive Surgery, Department of Surgery, Washington University, St. Louis, Missouri

Contact: yeea@wustl.edu

\section{Licensing}

The authors have chosen to license this content under a Creative Commons Attribution, NonCommercial, NoDerivatives 4.0 International License.

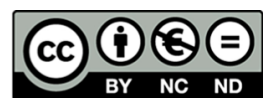

Authorization for publication of images from Pernkopf's atlas has been granted for use in this article only. The atlas images must remain within the context of this article for open-access, scholarship and educational use. The atlas images in this article may not be removed from this article, nor reproduced, nor distributed, outside of the context of this article, for scholarly, education or commercial purposes, without the expressed permission of the Josephinum.

\section{Image Credits}

The Journal of Biocommunication wishes to thank the Josephinum and the Medical University of Vienna for approving the publication of Pernkopf atlas images that are used within this Special Issue. These images may appear on the cover, in the Table of Contents, and as figures within articles and are acknowledged with the following image credit:

Josephinum - Ethik, Sammlungen und Geschichte der Medizin, MedUni Wien

Josephinum - Ethics, Collections and History of Medicine, MedUni Vienna

\section{Conflict of Interest Statement}

The Journal of Biocommunication Management Board and Editors believe that transparency in academic research is essential. Our $J B C$ authors are now required to disclose any possible conflict of interest when submitting a manuscript. In accordance with the Journal of Biocommunication's editorial policy, no potential conflict of interest has been reported or declared by the authors. 